\title{
Short communication: Accuracy of corpus luteum color flow Doppler ultrasonography to diagnose nonpregnancy in dairy cows on day 21 after insemination
}

\author{
J. Dubuc, ${ }^{*} \odot$ J. Houle, M. Rousseau, J.-P. Roy, $\odot$ and S. Buczinski $\odot$ \\ Faculté de Médecine Vétérinaire, Université de Montréal, 3200, rue Sicotte, Saint-Hyacinthe, Québec, J2S 2M2, Canada
}

\begin{abstract}
The main objective of this study was to determine the accuracy of corpus luteum color flow Doppler ultrasonography (CLCFDU) to diagnose nonpregnant dairy cows $21 \mathrm{~d}$ after insemination. A secondary objective was to determine the accuracy of other indirect tests such as corpus luteum size and progesteronemia. Data from 1,632 Holstein cows (10 commercial herds) were used for the analysis in this prospective cohort study. The herds were visited weekly by a veterinarian and an animal health technician. During farm visits, cows were examined on d 21 after insemination using transrectal B-mode ultrasonography to quantify the presence and size of the corpus luteum. After identification of the corpus luteum, CLCFDU was performed and scored as D0, D1, D2, or D3 when $10 \%$ or less, between 11 and $30 \%$, between 31 and $60 \%$, or $61 \%$ or more of the corpus luteum surface was colored, respectively. A blood sample from coccygeal vessels was also collected to quantify progesteronemia. Farmers were blinded to these findings and no intervention was performed following examination. On d 32 after insemination, the cows were examined by the regular herd veterinarian using transrectal palpation and B-mode ultrasonography to determine whether the cows were pregnant or not (the reference test). Statistical analyses were conducted using $2 \times 2$ contingency tables. The apparent prevalence, sensitivity, specificity, positive predictive value, and negative predictive value of CLCFDU for predicting nonpregnancy were 22.0, 36.6, 99.0, 98.1, and $52.0 \%$, respectively, when using D0 only as the diagnostic criterion; they were 47.2, 76.4, 94.8, 93.5, and $73.8 \%$, respectively, for $\mathrm{D} 0+\mathrm{D} 1$ criteria. The same measures for cows with a corpus luteum $<15 \mathrm{~mm}$ were $8.0,11.7,97.5,86.9$, and $43.4 \%$, respectively, and they were $51.9,67.4,70.4,76.6$, and $60.0 \%$, respectively,
\end{abstract}

Received July 8, 2019.

Accepted October 7, 2019.

*Corresponding author: Jocelyn.dubuc@umontreal.ca for progesteronemia $<1 \mathrm{ng} / \mathrm{mL}$. The measures of accuracy of CLCFDU to identify nonpregnant cows on d 21 after insemination were high, and the apparent prevalence varied depending on the diagnostic criteria used. The measures of accuracy of corpus luteum size $(<15 \mathrm{~mm})$ for the same purpose were high; however, apparent prevalence was low. The measures of accuracy of progesteronemia $(<1 \mathrm{ng} / \mathrm{mL})$ were low. In conclusion, CLCFDU had excellent accuracy to diagnose nonpregnancy in dairy cows on d 21 after insemination. Key words: dairy cow, Doppler, pregnancy, corpus luteum, progesterone

\section{Short Communication}

Pregnancy diagnosis on dairy farms helps to identify nonpregnant cows to rebreed them and improve reproductive efficiency (Fricke et al., 2016). Transrectal palpation with or without the use of B-mode ultrasonography is a direct pregnancy test commonly used on farms (Fricke et al., 2016). Indirect pregnancy tests can also be used to facilitate reproductive management on farms. For example, corpus luteum size is sometimes used to identify nonpregnant cows to implement rebreeding strategies (Kelley et al., 2016). Pregnancyassociated glycoproteins and progesterone in blood or milk can also be quantified to achieve the same goal (Romano and Larson, 2010; LeBlanc, 2013; Fricke et al., 2016).

Color flow Doppler ultrasonography has been used to monitor blood flow in reproductive tract organs of cows and ewes (Bollwein et al., 2016; Beltrame et al., 2017; Arashiro et al., 2018). The use of corpus luteum color flow Doppler ultrasonography (CLCFDU) to monitor blood flow has been shown to accurately identify nonpregnant dairy cows $20 \mathrm{~d}$ after insemination (Siqueira et al., 2013), with the absence of blood flow indicating the absence of pregnancy. It has also been shown to be a useful tool to measure luteal blood flow in Bos indicus dairy cows during the 3 wk after insemination (Hassan et al., 2019), as well as for the selection of recipients for embryo transfer in beef cows (Pugliesi et al., 2019). 
Although the body of literature on the use of CLCFDU in dairy cows has increased over the last 5 yr, much remains unknown. Its accuracy for identifying nonpregnant cows among 317 cows as soon as 20 d after insemination, as reported by Siqueira et al. (2013), is impressive and could influence how reproduction is managed on dairy farms. Being able to identify nonpregnant cows and rebreed them at $\mathrm{d} 21$ after insemination could help establish a sustainable strategy for commercial dairy farms (with reproductive exams always performed on the same day of the week).

Therefore, the main objective of this study was to determine the accuracy of CLCFDU to diagnose nonpregnancy in dairy cows $21 \mathrm{~d}$ after insemination. A secondary objective of this study was to determine the accuracy of other indirect tests - corpus luteum size and progesteronemia - for the same purpose. The hypothesis was that CLCFDU, corpus luteum size, and progesteronemia would have high accuracy to identify nonpregnant cows but would not be accurate tests to identify pregnant cows.

A prospective cohort study was conducted in 10 Holstein herds conveniently selected within the client list of the bovine ambulatory clinic of the Faculté de médecine vétérinaire of the Université de Montréal (StHyacinthe, QC, Canada). Herd inclusion in the study was based on willingness to participate, on being within a 1-h drive of St-Hyacinthe (QC, Canada), on having a high proportion of their breeding based on ovulation synchronization strategies, and on having an appropriate farm setup to perform data collection. Once a farmer agreed to participate, the herd was visited every week by a veterinarian and an animal health technician. Farm visits were always on the same day of the week and this day was targeted based on the herd breeding strategy.

A sample size of 1,650 cows was estimated for the study based on an expected sensitivity or specificity of $95 \%$ for the tests (CLCFDU, corpus luteum size, and progesteronemia), a minimal acceptable confidence level limit of $90 \%$, an expected prevalence of nonpregnant cows of $20 \%$ (Flahault et al., 2005), and a loss to follow-up of $10 \%$ of the cows.

In participating herds, only cows were enrolled (no nulliparous animals) and they were exclusively bred by AI. The voluntary waiting period in these herds was 50 d. All cows were bred using an ovulation synchronization protocol for the first breeding. Depending on the herd, between 78 and $100 \%$ of subsequent breedings were performed with ovulation synchronization protocols.

During the farm visits, all cows at d 21 after AI underwent transrectal ultrasonographic examination (Ex-
aGo, IMV Imaging, Angoulême, France) of the ovaries using the B-mode function (rectal probe; frequency 7.5 $\mathrm{MHz}$; dynamic range: $60 \mathrm{~dB}$ ) to quantify precisely the presence and size of corpus luteum. Size was quantified by measuring the diameter of the corpus luteum ( $\mathrm{mm}$ ). Once identified, the corpus luteum was examined using the color flow Doppler function (frequency: $6.0 \mathrm{MHz}$; pulse repetition frequency: 4,000 Hz). A semi-objective scoring chart was used to classify corpora lutea as D0, D1, D2, or D3 when $10 \%$ or less, between 11 and 30\%, between 31 and $60 \%$, or $61 \%$ or more of the corpus luteum surface was colored, respectively. In cases of a cystic corpus luteum, the surface used for analysis excluded the area filled with fluid. Each corpus luteum was examined twice during the same transrectal palpation and the highest score was retained. Farmers were blinded to the ultrasonographic results and no intervention was performed on cows based on the study results.

In a subsample of 200 cows, a second veterinarian (blinded to the first veterinarian's results) also performed a complete ultrasonographic examination (performed first in 100 cows and second in 100 other cows). The results from both veterinarians were compiled independently to calculate the inter-observer agreement. To do this, CLCFDU videos were taken from 100 cows and compiled; they were reviewed and scored 1 mo later by the same veterinarian (blinded to the farm results). To calculate intra-observer agreement, a subsample of 100 cows were randomly re-examined at d 21 after insemination by the first author (J. Dubuc), who was blinded to the previous results.

After the CLCFDU examination, cows were bled from coccygeal vessels using a dry blood collection evacuated tube (BD Vacutainer, Becton Dickinson and Co., Franklin Lakes, NJ). The blood samples were allowed to clot, transported on ice to the laboratory, and centrifuged $\left(3,000 \times g, 5 \mathrm{~min}, 4^{\circ} \mathrm{C}\right)$. Serum was extracted and frozen at $-20^{\circ} \mathrm{C}$. Serum samples were sent to the veterinary diagnostic service of the Université de Montréal (St-Hyacinthe, QC, Canada) for quantification of progesterone using a sequential ELISA (Immunlite, Siemens, Mississauga, ON, Canada) validated for use in cattle (Martin et al., 2007). The analytical sensitivity of the test was $0.2 \mathrm{ng} / \mathrm{mL}$, and the inter- and intraassay coefficients of variation of this test were 8.1 and $6.5 \%$, respectively.

All participating cows were examined by the regular herd veterinarian on d 32 after insemination using transrectal palpation and B-mode ultrasonographic examination. Cows were classified as pregnant (presence of embryonic vesicle with heartbeat) or nonpregnant; the latter were subsequently synchronized for breeding according to usual farm procedures. 
Table 1. Prevalence, sensitivity, specificity, positive predictive value (PPV), negative predictive value (NPV), and accuracy of 3 tests (corpus luteum color flow Doppler ultrasonography, corpus luteum size, and progesteronemia) performed on d 21 after AI for predicting nonpregnancy on d 32 after AI in 1,632 Holstein cows enrolled in an observational study

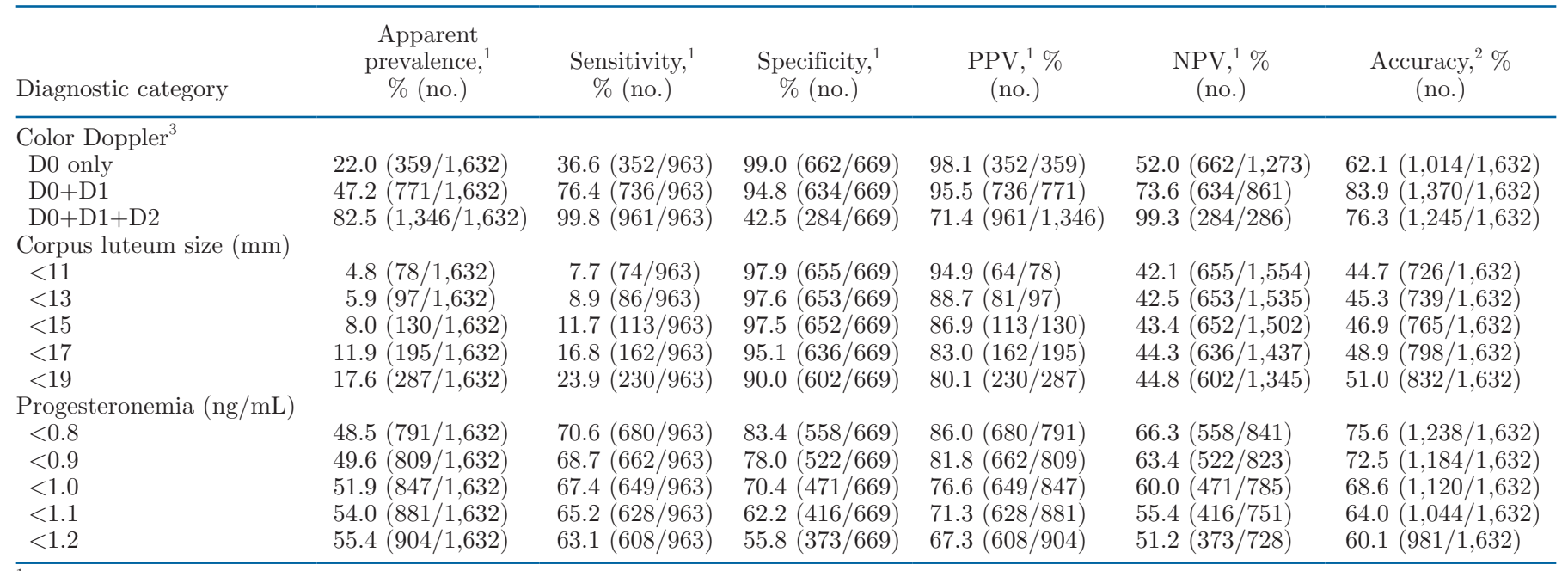

${ }^{1}$ Of nonpregnancy.

${ }^{2}$ True positive + true negative/all examined cows.

${ }^{3}$ D0 refers to $10 \%$ or less of the corpus luteum surface being colored; D1 refers to 11 to $30 \%$ of the corpus luteum surface being colored; D2 refers to 31 to $60 \%$ of the corpus luteum surface being colored.

Statistical analyses were performed with SAS (SAS Institute Inc., Cary, NC). The cow was the unit of interest. Descriptive statistics were computed using the FREQ and MEANS procedures. Contingency $2 \times 2$ tables were created using the FREQ procedure. Measures of accuracy, including sensitivity, specificity, positive predictive value (PPV), negative predictive value (NPV), and accuracy (true positive + true negative/ all examined cows) to identify nonpregnancy were calculated for these tables. The reference test was nonpregnancy status at d 32 after AI. For the CLCFDU results, data were dichotomized using various categories (D0 only; D0+D1; D0+D1+D2). A $2 \times 2$ table was built for each category and accuracy measures were computed each time. A similar approach was used to dichotomize corpus luteum size $(<11,<13,<15,<17$, and $<19 \mathrm{~mm})$ and progesteronemia $(<0.8,<0.9,<1.0,<1.1$, and $<1.2$ $\mathrm{ng} / \mathrm{mL}$ ). Inter- and intraobserver agreement measures (kappa values) for CLCFDU were computed using the FREQ procedure (Dohoo et al., 2003).

A total of 1,681 cows from 10 herds were enrolled in this observational study. Herd size ranged from 70 to 300 milking cows. Forty-nine cows were examined on d 21 after insemination but were removed from the herd between d 21 and 32. Therefore, 1,632 cows were eligible for inclusion in statistical analyses. On $\mathrm{d}$ 32 after insemination, $41.0 \%(669 / 1,632)$ of the cows were pregnant and $59.0 \%(963 / 1,632)$ were nonpregnant (true prevalence of nonpregnancy). On d 21 after insemination, the distribution of CLCFDU scores was D0: $22.0 \%(359 / 1,632)$, D1: $25.3 \%(412 / 1,632)$, D2: $35.2 \%(575 / 1,632)$, and D3: $17.5 \%(286 / 1,632)$. The median corpus luteum size on d 21 after insemination was $22 \mathrm{~mm}(6-38 \mathrm{~mm})$. The median progesteronemia on d 21 after insemination was $2.6 \mathrm{ng} / \mathrm{mL}(0.2-9.7 \mathrm{ng} /$ $\mathrm{mL}$ ). The apparent prevalence, sensitivity, specificity, PPV, and NPV of CLCFDU, corpus luteum size, and the progesteronemia categories to identify nonpregnancy are presented in Table 1. Inter- and intraobserver agreement (weighted kappa) for CLCFDU were 0.90 and 0.94 , respectively. Examination time took between 1 and 3 min per cow.

Based on the hypotheses, the study focused on validating the accuracy of CLCFDU, corpus luteum size, and progesteronemia to diagnose nonpregnant cows. The accuracy measures reported here should be interpreted in that context (especially when comparing with other studies that might have used comparison with pregnancy status). The accuracy measures for diagnosing nonpregnancy using CLCFDU were high $(99.0 \%$ for the D0 only category and $94.8 \%$ for D0+D1 category) and similar to those reported by Siqueira et al. (2013), although the scoring techniques and the formulas for calculation of PPV and NPV were slightly different. The results from both studies support the fact that CLCFDU can be used to accurately diagnose nonpregnancy on d 20 and 21 after insemination. The apparent prevalence of nonpregnancy on d 21 after insemination 
when using CLCFDU varied depending on which diagnostic category was used; $22.0 \%$ for D0 only and $47.2 \%$ for $\mathrm{D} 0+\mathrm{D} 1$. The latter is closer to the true prevalence of $59.0 \%$; however, it implies that the specificity and PPV to identify nonpregnant cows are 94.8 and $95.5 \%$, respectively. A user who would prefer to minimize the risk of diagnosing a nonpregnancy in an animal that is actually pregnant should use the D0 only category (specificity: 99.0\%; PPV: 98.1\%). It should also be kept in mind that CLCFDU is not a good test to confirm that an animal is pregnant, because a high corpus luteum blood flow on d 21 after insemination does not automatically mean that the cow will be pregnant on $\mathrm{d}$ 32 after insemination. For example, the proportions of false negatives in our study were 48.0, 26.4, and $0.7 \%$ for $\mathrm{D} 0, \mathrm{D} 0+\mathrm{D} 1$, and $\mathrm{D} 0+\mathrm{D} 1+\mathrm{D} 2$ scores, respectively.

A small corpus luteum size $(<15 \mathrm{~mm})$ is sometimes used to identify nonpregnant cows (Kelley et al., 2016). Based on the present study results, the accuracy of this approach for diagnosing nonpregnancy was $97.5 \%$; however, it lead to a low apparent prevalence of $8.0 \%$. This means that when examining 100 cows using this diagnostic approach on d 21 after insemination, only 8 cows (out of a true potential of 59) would be diagnosed nonpregnant. This method requires a lot of effort to identify only 8 cows, which could limit the potential benefit of implementing it. Increasing the corpus luteum size diagnostic criteria could help identify more nonpregnant cows, but even then, the apparent prevalence would remain relatively low (no more than $17.5 \%)$.

Low progesteronemia $(<1.0 \mathrm{ng} / \mathrm{mL})$ is sometimes used to identify cows in luteolysis (Stevenson and Phatak, 2010). Our study results show that its accuracy to diagnose nonpregnancy is low. This might be influenced by extended luteal phases and is consistent with other studies (Fricke et al., 2016). When comparing these results with other studies, the sensitivity of the analytical method used must be considered, as well as factors such as animal weight, breed, and parity. Therefore, this test should be used and interpreted with care.

Although comparing test results from d 21 and 32 after insemination is not ideal (comparing 2 tests on the same day would be preferable), it should not have influenced the specificity and PPV for predicting nonpregnancy. In other words, cows that were truly nonpregnant on d 21 after insemination are still going to be nonpregnant on $\mathrm{d} 32$. However, interpretation should carried out carefully regarding the sensitivity and NPV of nonpregnancy; the tests performed on d 21 could only tell if a cow was possibly pregnant. Therefore, CLCFDU should not be used to identify pregnant cows. The apparent prevalence data should also be interpreted with care, because cows might have been pregnant on d 21 and have lost the embryo before d 32. This could have biased our apparent prevalence estimation of nonpregnancy.

In conclusion, CLCFDU had high accuracy to diagnose nonpregnancy in dairy cows on d 21 after insemination, and its apparent prevalence varied depending on the diagnostic criteria used. The accuracy of corpus luteum size $(<15 \mathrm{~mm})$ for the same purpose was high; however, its apparent prevalence was low. The accuracy of progesteronemia $(<1 \mathrm{ng} / \mathrm{mL})$ was low. To implement the use of CLCFDU on farms, future studies should investigate which rebreeding strategies increase the subsequent reproductive performance.

\section{ACKNOWLEDGMENTS}

This project was financially supported by the "Fonds de recherche clinique Zoetis" of the bovine ambulatory clinic (Université de Montréal, St-Hyacinthe, QC, Canada), by the "Fondation du Centre Hospitalier Universitaire Vétérinaire" (Université de Montréal), by the "Centre de Recherche en Reproduction et Fertilité" (Université de Montréal), and by Zoetis Animal Health (Kirkland, QC, Canada). The authors thank Jean-Philippe Pelletier (St-Hyacinthe, QC, Canada) for his technical support and the dairy producers for their participation in the study. The authors declare no conflict of interest.

\section{REFERENCES}

Arashiro, E. K. N., R. Ungerfeld, R. P. Clariget, P. H. N. Pinto, M. F. A. Balaro, G. M. Bragança, L. S. Ribeiro, J. F. D. Fonseca, and F. Z. Brandão. 2018. Early pregnancy diagnosis in ewes by subjective assessment of luteal vascularisation using colour Doppler ultrasonography. Theriogenology 106:247-252. https://doi.org/10.1016/j .theriogenology.2017.10.029.

Beltrame, R. T., C. Covre, L. B. Littig, A. D. B. Martins, C. R. Quirino, A. B. Junior, and R. L. D. da Costa. 2017. Transrectal Doppler sonography of uterine blood flow in ewes during pregnancy. Theriogenology 91:55-61. https://doi.org/10.1016/j.theriogenology .2016 .12 .026 .

Bollwein, H., M. Heppelmann, and J. Lüttgenau. 2016. Ultrasonographic Doppler use for female reproduction management. Vet. Clin. North Am. Food Anim. Pract. 32:149-164. https://doi.org/ 10.1016/j.cvfa.2015.09.005.

Dohoo, I., W. Martin, and H. Stryhn. 2003. Veterinary Epidemiologic Research. 1st ed. AVC Inc., Charlottetown, PE, Canada.

Flahault, A., M. Cadilhac, and G. Thomas. 2005. Sample size calculation should be performed for design accuracy in diagnostic test studies. J. Clin. Epidemiol. 58:859-862. https://doi.org/10.1016/j .jclinepi.2004.12.009.

Fricke, P. M., A. Ricci, J. O. Giordano, and P. D. Carvalho. 2016. Methods for and implementation of pregnancy diagnosis in dairy cows. Vet. Clin. North Am. Food Anim. Pract. 32:165-180. https: //doi.org/10.1016/j.cvfa.2015.09.006.

Hassan, M., U. Arshad, M. Bilal, A. Sattar, M. Avais, H. Bollwein, and N. Ahmad. 2019. Luteal blood flow measured by Doppler ul- 
trasonography during the first three weeks after artificial insemination in pregnant and non-pregnant Bos indicus dairy cows. J. Reprod. Dev. 65:29-36. https://doi.org/10.1262/jrd.2018-084.

Kelley, D. E., L. Ibarbia, R. Daetz, J. H. Bittar, C. A. Risco, J. E. P. Santos, E. S. Ribeiro, and K. N. Galvão. 2016. Combined use of progesterone inserts, ultrasonography, and GnRH to identify and resynchronize nonpregnant cows and heifers 21 days after timed artificial insemination. Theriogenology 85:230-237. https://doi .org/10.1016/j.theriogenology.2015.09.052.

LeBlanc, S. J. 2013. Short communication: Field evaluation of a pregnancy confirmation test using milk samples in dairy cows. J. Dairy Sci. 96:2345-2348. https://doi.org/10.3168/jds.2012-6414.

Martin, J. L., K. A. Vonnahme, D. C. Adams, G. P. Lardy, and R. N. Funston. 2007. Effects of dam nutrition on growth and reproductive performance of heifer calves. J. Anim. Sci. 85:841-847. https: //doi.org/10.2527/jas.2006-337.

Pugliesi, G., G. Dalmaso de Melo, J. B. Silva, A. S. Carvalhêdo, E. Lopes, E. de Siqueira Filho, L. A. Silva, and M. Binelli. 2019 Use of color-Doppler ultrasonography for selection of recipients in timed-embryo transfer programs in beef cattle. Theriogenology 135:73-79. https://doi.org/10.1016/j.theriogenology.2019.06.006.
Romano, J. E., and J. E. Larson. 2010. Accuracy of pregnancy specific protein-B test for early pregnancy diagnosis in dairy cattle. Theriogenology 74:932-939. https://doi.org/10.1016/j.theriogenology 2010.04.018.

Siqueira, L. G. B., V. S. Areas, A. M. Ghetti, J. F. Fonseca, M. P. Palhao, C. A. C. Fernandes, and J. H. M. Viana. 2013. Color Doppler flow imaging for the early detection of nonpregnant cattle at 20 days after timed artificial insemination. J. Dairy Sci. 96:64616472. https://doi.org/10.3168/jds.2013-6814.

Stevenson, J. S., and A. P. Phatak. 2010. Rates of luteolysis and pregnancy in dairy cows after treatment with cloprostenol or dinoprost. Theriogenology 73:1127-1138. https://doi.org/10.1016/j .theriogenology.2010.01.014.

\section{ORCIDS}

J. Dubuc ๑ https://orcid.org/0000-0003-1013-8372

J.-P. Roy (ㄷ) https://orcid.org/0000-0002-0444-2303

S. Buczinski $\odot$ https://orcid.org/0000-0002-8460-4885 